OPEN ACCESS

Approved by:

Frontiers in Genetics Editorial Office,

Frontiers Media SA, Switzerland

${ }^{*}$ Correspondence:

Tao Yu

yutao0112@qdu.edu.cn;

dachao1201@hotmail.com

Hui Xin

xinhuiqy@163.com

tThese authors have contributed equally to this work

Specialty section: This article was submitted to

RNA

a section of the journal

Frontiers in Genetics

Received: 21 February 2019

Accepted: 22 February 2019

Published: 15 March 2019

Citation:

Liu S, Yang Y, Jiang S, Xu H, Tang N,

Lobo A, Zhang R, Liu S, Yu T and Xin H (2019) Corrigendum:

MiR-378a-5p Regulates Proliferation and Migration in Vascular Smooth Muscle Cell by Targeting CDK1.

Front. Genet. 10:193

doi: $10.3389 /$ fgene.2019.00193

\section{Corrigendum: MiR-378a-5p Regulates Proliferation and Migration in Vascular Smooth Muscle Cell by Targeting CDK1}

\author{
Shaoyan Liu ${ }^{1 \dagger}$, Yanyan Yang ${ }^{2 \dagger}$, Shaoyan Jiang ${ }^{3}$, Hong Xu ${ }^{4}$, Ningning Tang ${ }^{2}$, Amara Lobo ${ }^{1}$, \\ Rui Zhang ${ }^{1}$, Song Liu ${ }^{1}$, Tao Yu ${ }^{2 *}$ and Hui Xin ${ }^{1 *}$ \\ ${ }^{1}$ Department of Cardiology, The Affiliated Hospital of Qingdao University, Qingdao, China, ${ }^{2}$ Institute for Translational \\ Medicine, Qingdao University, Qingdao, China, ${ }^{3}$ Department of Cardiology, The Affiliated Cardiovascular Hospital of Qingdao \\ University, Qingdao, China, ${ }^{4}$ Department of Orthodontic, The Affiliated Hospital of Qingdao University, Qingdao, China
}

Keywords: miR-378a-5p, vascular smooth muscle cell, stent-restenosis, proliferation, migration, atherosclerosis, CDK1

\section{A Corrigendum on}

MiR-378a-5p Regulates Proliferation and Migration in Vascular Smooth Muscle Cell by Targeting CDK1

by Liu, S., Yang, Y., Jiang, S., Xu, H., Tang, N., Lobo, A., et al. (2019). Front. Genet. 10:22. doi: 10.3389/fgene.2019.00022

In the original article, we neglected to include the funder "National Natural Science Foundation of China," "81870331" to TY.

Additionally, there was an error in affiliation 3. Instead of "Department of Cardiology, The Affiliated Hospital of Qingdao University, Qingdao, China," it should be "Department of Cardiology, The Affiliated Cardiovascular Hospital of Qingdao University, Qingdao, China."

The authors apologize for these errors and state that this does not change the scientific conclusions of the article in any way. The original article has been updated.

Copyright () 2019 Liu, Yang, Jiang, Xu, Tang, Lobo, Zhang, Liu, Yu and Xin. This is an open-access article distributed under the terms of the Creative Commons Attribution License (CC BY). The use, distribution or reproduction in other forums is permitted, provided the original author(s) and the copyright owner(s) are credited and that the original publication in this journal is cited, in accordance with accepted academic practice. No use, distribution or reproduction is permitted which does not comply with these terms. 